\title{
Evaluating Postdoctoral Dental Candidates: Assessing the Need and Recommendations for a National Qualifying Examination
}

\author{
Abby J. Brodie, D.M.D., M.S.; Heidi C. Crow, D.M.D., M.S.; Robert M. Eber, D.D.S., \\ M.S.; Robert Handysides, D.D.S.; Roy Holexa, D.D.S.; Sudarat Kiat-amnuay, D.D.S., M.S.; \\ Heiko Spallek, D.M.D., Ph.D., M.S.B.A.(CIS) \\ Abstract: Increasingly, U.S. dental schools report pass/fail grades and do not rank students. In addition, the Joint Commission on \\ National Dental Examinations will report National Board Dental Examination (NBDE) scores as pass/fail after January 1, 2012. \\ This article discusses how these changes will force postdoctoral dental program directors to modify how they assess candidates \\ and how noncognitive evaluations might enhance those assessments. The authors propose developing a national qualifying \\ examination for postdoctoral dental programs that will measure knowledge, decision making, and noncognitive traits including \\ empathy, self-confidence, integrity, and emotional intelligence. Without NBDE scores, class rank, and GPA as a basis for decision \\ making, a single national qualifying examination would assist postdoctoral programs in selecting high-quality candidates based \\ on knowledge, critical thinking skills, and noncognitive traits.
}

\begin{abstract}
Dr. Brodie is Associate Professor and Associate Dean for Curriculum and Educational Affairs, Nova Southeastern University College of Dental Medicine; Dr. Crow is Associate Professor, Oral Diagnostic Sciences, and Associate Dean, Advanced Education, University at Buffalo School of Dental Medicine; Dr. Eber is Clinical Professor and Director, Healthcare Delivery Pathway Program, University of Michigan School of Dentistry; Dr. Handysides is Associate Professor and Chair of Endodontics, Loma Linda University School of Dentistry; Dr. Holexa is Clinical Associate Professor and Comprehensive Care Unit Director, Arizona School of Dentistry \& Oral Health, A.T. Still University; Dr. Kiat-amnuay is Associate Professor and Director, Postgraduate General Dentistry Clinics, University of Texas Health Science Center at Houston Dental Branch; and Dr. Spallek is Associate Professor and Associate Dean, Office of Faculty Development and Information Management, Dental Public Health, Center for Dental Informatics, University of Pittsburgh School of Dental Medicine. The authors were members of the 2010 class of the American Dental Education Association's Leadership Institute. Direct correspondence and requests for reprints to Dr. Abby J. Brodie, Nova Southeastern University College of Dental Medicine, 3200 S. University Drive, Fort Lauderdale, FL 33328; 954-262-7342 phone; 954-262-3293 fax; abrodie@nsu.nova.edu.
\end{abstract}

Keywords: postdoctoral dental education, postgraduate dental education, admissions criteria, holistic admissions practices, national qualifying examination

$\mathrm{C}$ hoosing among candidates for postdoctoral dental educational programs remains one of the most critical decisions facing dental higher education, while the means by which we currently assess applicants to these programs are undergoing significant changes. Since 2004, applications to all postdoctoral dental programs have increased 10 percent, while enrollment has increased only 6 percent. Application numbers vary among programs, but there are, on average, fifteen applications for every open position, with the highest being thirty-six applications per position in oral and maxillofacial surgery. ${ }^{1}$ From this competitive applicant pool, programs seek the best-qualified candidates who are capable of working well with other students, faculty mem- bers, and patients. In addition, they want to select candidates who will be successful future clinicians, researchers, educators, and leaders in dentistry. One of the primary criteria traditionally used for selecting candidates will no longer be available after January 1, 2012. After that date, National Board Dental Examination (NBDE) Parts I and II scores will be reported as pass/fail. ${ }^{2}$

With the impending change in reporting of NBDE scores in mind, the purposes of this article are to review currently used means of evaluating candidates for postdoctoral dental programs and to make recommendations for the development of a new qualifying examination. Resident selection practices, implications for the profession, and considerations 
for the development of a qualifying exam that will demonstrate validity in evaluating professionalism, personality, ethics, social skills, emotional stability, and attitude, in addition to the traditional measurements of dental knowledge and critical thinking skills, will be addressed. The authors were fellows of the American Dental Education Association (ADEA) Leadership Institute and represent a diverse sample of dental schools across the United States. We share the conviction that the time for a more-defining postdoctoral qualifying exam is now.

\section{Current Assessment Practices}

Traditional means of evaluating applicants for postdoctoral dental positions have included NBDE Part I and II scores, dental school grade point average (GPA), class rank, recommendation letters, personal statements, and one-on-one interviews. The first three criteria-NBDE scores, GPA, and class rank - are often used to determine which candidates will be interviewed. For example, in one survey study, pediatric dentistry program directors ranked the following criteria from most to least important for selecting residents: NBDE scores, dental school clinical grades, class rank, and GPA. ${ }^{3}$

Residency program directors in medicine historically have filled open positions by "adding up scores" because some have felt this was the best means available although numbers alone may fail to adequately define the best candidates. ${ }^{4}$ We believe it imperative that a reliable and validated examination be developed that assesses noncognitive or "soft" skills in addition to knowledge and critical thinking. We acknowledge the difficulties associated with developing, testing, and implementing an instrument that exhibits sufficient validity and reliability; however, we feel that this is a crucial component for best evaluating all candidates.

\section{GPA and Class Rank}

Academic achievement historically has been touted as the premier means of evaluation. Postdoctoral dental programs have traditionally relied on an applicant's grades, class rank, letters of recommendation, and NDBE scores in determining whom to interview as well as who would likely be successful in an advanced educational program. ${ }^{3,5}$ It is difficult, however, to compare GPAs or course grades across dental schools. It is reasonable to assume that there are differences in grading practices and rigor between schools, making it difficult to make direct comparisons of students from different institutions. In addition, some schools have eliminated letter grades altogether and instead report course grades as pass/ fail. As a result, postdoctoral dental program directors have also relied on class rankings to determine how one candidate compares to others at his or her school. A significant number of dental schools, however, no longer report specific class rankings for students. A recent study of orthodontic applicants noted that over 50 percent of applicants' schools either did not rank students or did not report their rank. ${ }^{6}$ Without GPA and class rank data, postdoctoral program directors must rely on letters of recommendation as the sole pre-interview criterion for screening students from certain schools. Unfortunately, even though many directors consider letters of recommendation critical to the selection of candidates, ${ }^{3}$ studies of such letters used for medical residencies have shown that they tend to be positively biased and are not generally useful for discriminating differences between candidates. ${ }^{7}$ Similarly, an applicant's personal statement may provide insight into his or her motives and written communication skills, but it is impossible to determine if the applicant wrote it independently. The value of the personal statement therefore is questionable. ${ }^{8,9}$

Of even greater concern is how to determine academic achievement for individuals graduating from non-Canadian international dental schools. Since 1956, U.S. and Canadian dental school accrediting bodies have recognized each other's accredited predoctoral education programs as equivalent; however, there currently is no similar agreement with other international dental schools. Consequently, program directors must independently try to determine equivalency or require the applicant use a member service of the National Association of Credential Evaluation Services to determine equivalency. This still fails to provide sufficient information about the curriculum the applicant completed. In addition, Test of English as a Foreign Language (TOEFL) or International English Language Testing System (IELTS) scores may be needed to assess English fluency, and additional testing may be indicated to evaluate oral communication ability. 


\section{NBDE Scores}

Believing that board scores compensate for variances in grading between schools and for schools that do not report grades, program directors and admissions committees have used NBDE scores to compare candidates from different dental schools. NBDE scores have been reported as the most important factor considered when selecting candidates to interview for oral and maxillofacial programs ${ }^{5}$ and the most important criterion influencing the ranking of candidates by advanced education program directors in pediatric dentistry. ${ }^{3}$ An applicant who scores an 89 is assumed to know less than one who scores a 90 and would not be granted an interview. But because of the way the exam was designed and the statistics were performed, this way of comparing the two students is invalid.

We are not aware of any studies assessing the use of NBDE II scores in selecting candidates for postdoctoral dental education programs. Seniors usually take the NBDE II during December or later of their final predoctoral year. Therefore, NBDE II scores would not be available for ADEA Postdoctoral Application Support Service (PASS) application submission, which is usually in September; for interviews of selected applicants; nor even by the time program directors have to submit their rank lists through MATCH, which is during the first week of January.

The Joint Commission on National Dental Examinations (JCNDE) has expressed concern about using the NBDE in ways it sees as jeopardizing the veracity and violating the intent of the examination. Regarding the NBDE, the JCNDE has stated that "the purpose of the exam is to assist state boards in determining qualifications of dentists who seek licensure to practice dentistry." 10 The JCNDE has indicated that it is inappropriate to use NBDE scores to rank candidates for postdoctoral programs because the test is not intended for that purpose and is not valid or reliable in differentiating candidates beyond the pass/fail level. ${ }^{11}$ Considering the JCNDE states that board scores have no validity beyond the pass/ fail level, specialty programs could be at risk of lawsuits if they use NBDE scores as a criterion for ranking applicants. Addressing what it sees as the misuse of NBDE scores, the JCNDE has announced that scores will be reported only as pass or fail after January 1, 2012, thus eliminating them as a ranking tool for purposes of postdoctoral program selection. ${ }^{2}$

Without the ability to use NBDE scores to differentiate students based on knowledge and critical thinking skills, program directors will have to rely on other factors in their search for the best outcome in selecting candidates. In the case of oral and maxillofacial surgery programs that require an M.D. degree, there is concern that, without some valid indication of basic science and clinical knowledge, a resident could fail his or her United States Medical Licensing Examination (USMLE) on a first attempt. Such failure then requires remediation, potentially preventing the resident from progressing in the designated schedule of the combined programs. While programs have different requirements, failure in a second attempt may entail a leave of absence, and failure in a third attempt may result in forced resignation from the program. Contrary to the JCNDE's assertion that there is no correlation between NBDE scores and success in a postdoctoral dental program, a 2003 survey of dual degree oral and maxillofacial surgery/M.D. programs found that residents who scored 95 to 99 on the NBDE Part I were seventyfive times more likely to pass the USMLE Part I on the first attempt than residents who scored less than 90 on the NBDE Part I. ${ }^{12}$ The first attempt pass rate on the USMLE has been used as a positive indicator of resident performance, ${ }^{13}$ and certainly failing the examination has consequences for the student as well as the program itself.

\section{Components of a National Qualifying Exam for Postdoctoral Dental Education}

Questions arise as to what qualities a successful postdoctoral dental program applicant should possess and how they can be measured. An April 2010 ADEA survey of postdoctoral dental program directors found the following as the top qualities for successful candidates, in order of importance: team player, assuming responsibility, integrity, interpersonal/communication skills, and reliability (Eugene L. Anderson, ADEA). Various program directors and the various specialty boards and associations may differ in opinions about what constitutes a good candidate, and even within a specialty there may be no consensus concerning what constitutes an excellent candidate.

As a group of educators, however, we feel that all programs seek certain core characteristics in all 
applicants. These core values and characteristics are listed in Table 1. We will address the evaluation of these characteristics in the remainder of this section.

\section{Clinical and Basic Science Knowledge and Clinical Decision Making}

We believe that aspects of the current NBDE Parts I and II that assess clinical knowledge, clinical decision making, and basic science knowledge are necessary and should be incorporated into a national qualifying exam for postdoctoral dental programs. However, we feel that creation of new assessment methods provides an opportunity to assess factors, such as noncognitive and personality traits, that the NBDE fails to capture.

\section{Noncognitive Traits}

Due to their competitive academic nature, educators often encourage an environment that places a narrow focus on competency assessments at the expense of other crucial noncognitive skills. However, program directors generally acknowledge that candidates with the best scores do not necessarily become the most successful residents. A truly exceptional resident goes far beyond academics.

We believe that transcript grades are an external indicator of motivation and success that fail to adequately quantify the difficult-to-teach aspects of an applicant's character, such as critical thinking skills, emotional intelligence, communication skills, compassion, and integrity. Thus, evaluation of a candidate's potential for success should include not only the ability to complete a doctoral degree with a high GPA, but also the ability to demonstrate success in the areas of social, emotional, and compassionate behaviors. The future selection of postdoctoral dental program applicants may therefore depend upon the ability to assess the behavioral gifts, talents, and skills that are required to truly excel. This necessitates development of a new measurement instrument.

A national qualifying exam should promote competencies not only illustrating how smart postdoctoral candidates are or their training and expertise, but also their emotional intelligence: the ability, capacity, or skill to identify, assess, and manage the emotions of one's self, of others, and of groups. ${ }^{14} \mathrm{In}$ Emotional Intelligence, ${ }^{15}$ Daniel Goleman described the groundbreaking research that redefined what it means to be smart and discussed why emotional intelligence, defined as self-awareness, self-management, social awareness, and the ability to manage relationships, can matter more than IQ. Although not without its critics, ${ }^{16,17}$ Goleman's book presented a popular challenge to the IQ mystique - the false but widely embraced notion that what matters for success is one definition of intellect alone. Data from people in a variety of fields demonstrate which qualities mark a star performer and which human abilities make up the critical ingredients for excellence and

\begin{tabular}{|c|c|c|}
\hline Core Value or Characteristic & Current Method of Assessment & Proposed Method for Future Assessment \\
\hline Academic ability & $\begin{array}{l}\text { Class rank, GPA, predoctoral clinic } \\
\text { grades, NBDE }\end{array}$ & $\begin{array}{l}\text { Class rank, GPA, predoctoral clinic } \\
\text { grades, NPDQE }\end{array}$ \\
\hline Confidence without arrogance & Interview & NPDQE with PPI \\
\hline Critical thinking skills & NBDE & NPDQE \\
\hline $\begin{array}{l}\text { Diversity appreciation; cultural } \\
\text { competence }\end{array}$ & Interview, recommendation letters & Interview, NPDQE with PPI \\
\hline Effective communication skills & Interview, personal statement & Interview, NPDQE with PPI \\
\hline Emotional intelligence & Not assessed & NPDQE with PPI \\
\hline Empathy and compassion & Recommendation letters & NPDQE with PPI \\
\hline Ethics, moral judgment, integrity & Recommendation letters & NPDQE with PPI \\
\hline Work ethic & $\begin{array}{l}\text { Class rank, GPA, CV, recommendation } \\
\text { letters }\end{array}$ & $\begin{array}{l}\text { Class rank, GPA, CV, recommendation } \\
\text { letters }\end{array}$ \\
\hline Altruism/selflessness & CV showing community service & NPDQE with PPI \\
\hline
\end{tabular}

NBDE $=$ National Board Dental Examination

NPDQE=National Postdoctoral Dental Qualifying Examination (proposed)

$\mathrm{PPI}=$ Personal Potential Index 
leadership. In an attempt to further quantify emotional intelligence, Goleman conducted a review of research that evaluated the place of emotional intelligence in high-performing individuals. His results indicated that IQ was second to emotional intelligence in determining outstanding performance and that emotional intelligence skills were synergistic with cognitive skills, so that top performers have both. ${ }^{18}$

Adding an emotional intelligence measuring standard to the postdoctoral selection process would acknowledge that, by the time a student successfully completes the predoctoral curriculum, his or her intelligence (as traditionally defined) and technical expertise have been established. What is needed to go beyond what is already known is an attempt to assess abilities such as reflection, listening, and collaboration and values such as initiative, empathy, adaptability, compassion, and service. In our opinion, ideal residents also exhibit compassion, empathy, respect for diversity, and confidence without arrogance. These types of emotional intelligence and maturity traits are not usually evaluated, but are among the characteristics of a successful resident. Indirect attempts to measure these qualities have included evaluating the extent of participation in community service in postdoctoral applications ${ }^{6}$ or noting an expressed interest to serve in a dental Health Professional Shortage Area either during their residency or after training. In addition, characteristics of honesty, confidence, and empathy as assessed during the interview process have been ranked highly by postdoctoral program directors in prosthodontics. ${ }^{3}$ A standardized evaluation encompassing these traits that takes place prior to the interview would assist program directors and likely yield valid information.

\section{Personality Traits}

Do personality traits matter and can they be measured as part of the application and admissions criteria? In an article in the January 14, 2010, issue of The New York Times, Pauline W. Chen, M.D., asked, "Do we really need to be good at multiplechoice exams in order to be a good doctor?"19 Dr. Chen proposed that since there is no reliable way to evaluate personality, tests alone cannot guarantee that admitted applicants are also destined to become the best doctors. Furthermore, she argued, according to a study published in the Journal of Applied Psychol$o g y$, that there is another kind of exam that may be more predictive of how successful students will be in medicine: personality testing. ${ }^{20}$ In a decade-long study of more than 600 medical students in Belgium by three industrial and organizational psychologists from the United States and Europe, it was found that the results of the personality test had a striking correlation with the students' performance. Dr. Deniz S. Ones, a professor of psychology at the University of Minnesota and one of the authors of the study, argues that the noncognitive personality domain is an untapped area for medical school admissions since a perennial question that personality testing could help to answer is whether hard work can make up for differences in cognitive ability. "If a medical school is all about graduating great researchers, then I would tell them not to weigh the results of the personality test that heavily," Dr. Ones is quoted as saying in the New York Times article. "But if you want doctors who are practitioners, valued members in terms of serving the greater public, then you have to pay close attention to these results." ${ }^{19}$

In another study regarding cognitive and noncognitive selection criteria, Wood et al. compared objective measures of diagnostic radiology resident applicant performance with nonobjective measures such as conscientiousness and interpersonal skills in predicting performance. ${ }^{21}$ This study also evaluated the predictive usefulness of a behavioral selection interview tool, the AI (Accomplishment Interview). These investigators concluded that both cognitive and noncognitive variables are significant predictor criteria in resident selection, while at the same time failing to adequately predict resident performance.

To address the challenge of evaluating noncognitive traits associated with desirable applicants, the Educational Testing Service (ETS) is introducing a new tool: the Personal Potential Index (PPI; www.ets. org/ppi). In the PPI, professors and former supervisors rate six traits of the applicant's personality. According to the ETS, this is the first large-scale attempt to codify the elusive, subjective attributes that make up a successful graduate student. Although noncognitive skills are considered by many to be crucial to success in higher education, assessment of them needs to be standardized and testable. Any instrument needs to be tested for acceptability, feasibility, reliability, and validity in a measurement study.

\section{Discussion}

When one suggests pursuing a new testing model, it may raise as many questions as answers. Who should be involved in developing the test, for 
example? Our thought is that additional surveys of postdoctoral dental program directors, specialty boards, and associations may provide helpful data in developing new evaluation methods.

And what are the costs? We understand that the cost of developing a new national qualifying examination is a concern. The various specialties and postdoctoral program groups that would use the exam should share the initial costs of developing it, perhaps using a formula based on total membership of each organization or on the average yearly number of applicants each receives. The costs of development should eventually be recouped from testing fees. Another factor is that while small in comparison to average student debt upon graduation from dental school, a new examination would place an additional burden on all applicants and might discourage those who are economically disadvantaged. So should such an exam be mandatory for all postdoctoral program applicants or only for those wishing to specialize? The cost would increase if only the 20 percent who wish to specialize utilized the examination.

It may also be asked if the specialties should embrace one method of assessment or each develop its own exam. Many specialty programs are well on their way to embracing different forms of examinations. Some programs are considering mandating the Graduate Record Examination (GRE), previously utilized primarily for admission to master's and Ph.D. programs. The problem with a program-specific approach is that it would increase costs to individuals applying to more than one type of program and still fall short of the "untapped, noncognitive, personality domain." 16

These questions pertain to the acceptability and feasibility of developing a new exam. If postdoctoral dental programs collaborate to implement a new national qualifying exam, they also will need to plan to assess outcomes to determine the success or shortcomings of the new instrument.

\section{Conclusions and Recommendations}

In conclusion, we feel that a national qualifying examination for postdoctoral dental programs is needed because, among other reasons, NBDE scores will no longer be available after January 1, 2012. As a result, we make the following recommendations:
1. A new single qualifying examination for evaluating applicants to postdoctoral dental programs should be developed and implemented as soon as is feasible, with a goal of not later than January 2013.

2. The qualifying examination should include the following sections: understanding of basic and clinical sciences, critical thinking skills, emotional intelligence, and personality. The structure and content of the basic and clinical sciences and critical thinking skills portions of a new exam are topics for a different article.

3. The qualifying examination should be able to discriminate between individuals beyond the pass/fail level and be valid and reliable.

4. The qualifying examination should be developed with representation from all postdoctoral dental programs.

5. The qualifying examination will only be required of dental graduates seeking postdoctoral studies.

Developing this new examination will be a difficult and possibly contentious task; however, we believe that postdoctoral dental programs, students, patients, and the profession will be better served in the long term as a result.

\section{Acknowledgments}

The authors would like to thank Dr. N. Karl Haden, Director of the ADEA Leadership Institute, and Dr. Cecile A. Feldman, our group's mentor over the yearlong fellowship. This article would not have been possible without their guidance and encouragement. We would also like to thank Ms. Toni Fanelli for the hours of hard work organizing the events of the Leadership Institute.

\section{REFERENCES}

1. American Dental Association. 2008-09 survey of advanced dental education. Chicago: American Dental Association, 2010

2. Joint Commission on National Dental Examinations, American Dental Association. NBDE newsletter, spring 2009.

3. Majewski RF, da Fonseca MA, DeVries ES, Hu JC, Murdoch-Kinch CA. Factors influencing pediatric dental program directors' selection of residents and demographics of current directors. J Dent Educ 2009;73(3):338-44.

4. Gunderman RB, Jackson VP. Are NBME examination scores useful in selecting radiology residency candidates? Acad Radiol 2000;7(8):603-6.

5. Spina AM, Smith TA, Marciani RD, Marshall EO. A survey of resident selection procedures in oral and maxillofacial surgery. J Oral Maxillofac Surg 2000;58(6):660-6. 
6. Ardeshna AP, Fong CA. Characteristics of applicants who obtain interviews at orthodontic postgraduate programs. Angle Orthod 2010;80(2):373-7.

7. Stedman JM, Hatch JP, Schoenfeld LS. Letters of recommendation for the predoctoral internship in medical schools and other settings: do they enhance decision making in the selection process? J Clin Psychol Med Settings 2009;16(4):339-45.

8. Taylor CA, Weinstein L, Mayhew HE. The process of resident selection: a view from the residency director's desk. Obstet Gynecol 1995;85(2):299-303.

9. Max BA, Gelfand B, Brooks MR, Beckerly R, Segal S. Have personal statements become impersonal? An evaluation of personal statements in anesthesiology residency applications. J Clin Anesth 2010;22(5):346-51.

10. Joint Commission on National Dental Examinations. National Board Dental Examination, part II: 2010 guide. Chicago: American Dental Association, 2010.

11. Neumann LM, MacNeil RL. Revisiting the National Board Dental Examination. J Dent Educ 2007;71(10):1281-92.

12. Miloro M, Petersen T, Stoner J. Is there a correlation between performance on dental and medical board examinations? J Oral Maxillofac Surg 2003;61(6):701-6.

13. Dodson TB, Guralnick WC, Donoff RB, Kaban LB. Massachusetts General Hospital/Harvard Medical School MD oral and maxillofacial surgery program: a 30-year review. J Oral Maxillofac Surg 2004;62(1):62-5.
14. DulewiczV, Higgs M. Emotional intelligence: a review and evaluation study. J Manag Psychol 2000;15(4):341-72.

15. Goleman D. Emotional intelligence. New York: Bantam, 1995.

16. Paul AM. Promotional intelligence. Salon, June 28, 1999. At: www.salon.com/books/it/1999/06/28/emotional. Accessed: August 1, 2010.

17. Daus C, Ashkanasy N. Will the real emotional intelligence please stand up? On deconstructing the emotional intelligence "debate." Ind Organizational Psychologist 2003;41(2):69-72.

18. Goleman D. Working with emotional intelligence. New York: Bantam, 1998.

19. Chen PW. Do you have the "right stuff" to be a doctor? New York Times, January 14, 2010. At: www.nytimes. com/2010/01/15/health/14chen.html. Accessed: January 18,2010 .

20. Lievens F, Ones DS, Dilchert S. Personality scale validities increase throughout medical school. J Appl Psychol 2009;94(6):1514-35.

21. Wood PS, Smith WL, Altmaier EM, Tarico VS, Franken EA Jr. A prospective study of cognitive and noncognitive selection criteria as predictors of resident performance. Invest Radiol 1990;25(7):855-9. 